\title{
ENGEVISTA
}

Página da revista: http://www.uff.br/engevista/seer/

\section{Evaluation of the reaction conditions in the transesterification of canola oil for biodiesel production}

\author{
Sílvio Miguel Parmegiani Marcucci \\ Carina Akemi Araki \\ Renata Teresinha Kiffer \\ Murilo Pereira Moisés \\ Pedro Augusto Arroyo
}

\begin{abstract}
The development of renewable fuels has received great attention in recent years. Fatty acid esters, known as biodiesel, are promising for partially or total diesel replacement. Therefore, this work aimed to evaluate the reaction conditions for refined canola oil transesterification and the quality of biodiesel produced. The influence of different alkaline catalysts, catalyst amount, stirring rate, temperature, oil:alcohol molar ratio and alcohol type were assessed. The ester yield in the best reaction conditions were $96.1 \pm 1.26 \%$ for ethanol and $95.32 \pm 2.68 \%$ for methanol. The biodiesel produced was analyzed according to the ANP (Agência Nacional de Petróleo, Gás Natural e Biodiesel) quality norms. The esters showed good quality in relation to the cold filter plugging point, the oxidation stability and the cetane number.
\end{abstract}

Keywords: Ethanol, rapeseed oil, transesterification, alkaline catalyst, biodiesel. 


\section{Introduction}

Biodiesel is an alternative fuel, biodegradable, non-toxic and can be produced by renewable sources like vegetable oil and animal fats. Its use results in lower pollutants emissions compared to diesel oil and allow the balance between agriculture, economic development and the environmental (Meher et al., 2006). For these reason, biodiesel production can contribute to the decrease in oil dependence and to minimizing the environmental impact caused by fossil fuels (Demirbas et al., 2007; Kwon et al., 2015; Jenab et al., 2014).

In addition, biodiesel has advantages such as availability, combustion efficiency, high flash point, lubricity, lower sulfur content and aromatics (Knothe et al., 2005; Avhad and Marchetti, 2015; Silva et al., 2012; Luna et al., 2015). Regarding the environmental conditions for biodiesel production, the tropical climate associated with high sunlight and water availability and the rainfall regularity, make Brazil a leading country in the production of renewable energy (César et al., 2013; Bergmann et al., 2013; Khatiwada, et al., 2016).

The canola and soybean oil have a composition that result in a biodiesel with attractive quality (Ozcanli and Serin, 2011). In particular, canola oil has gained importance not only due to the growth of cultivation in many parts of the world but also because the oil yield obtained from oleaginous (between 34 and 40\%) is 2 times higher than that obtained from soybean and is often higher than another plants (Milazzo et al., 2013).

Another source used in biodiesel production is the acyl acceptor, mainly short-chain alcohols. In this regard, methanol is the most used because it has a higher reactivity and lower cost in some countries. However, ethanol can be used instead methanol because its less toxic and produced from renewable sources, such as sugar cane in Brazil (Li et al., 2013; Demirbas, 2005).

The commercial biodiesel generally is produced by alkaline transesterification. According Kwon et al. (2015) the reaction undergoes the effects related to the nature and concentration of the catalyst, agitation intensity, temperature, reaction time and the oil. The type and alcohol amount in the reaction also exert an influence on the ester yield, as well as on the biodiesel quality and reaction rate, due to the differences in reactivity regarding the nucleophilicity of the alkoxides and the miscibility with glyceride (Kulkarni et al., 2006).

Thus, the reaction parameters are of the great importance for the determination of the conditions in which the mixture of alkyl esters formed has the quality standards established by regulatory agencies. Therefore, the objective of this work was to determine the reaction conditions that would provide the highest esters yields for transesterification reaction of refined canola oil and characterize the biodiesel with respect of quality exigency for in ANP (National Agency of Petroleum, Natural Gas and Biodiesel). 


\section{Materials and methods}

\subsection{Feedstock and reagents}

The reactants used in the transesterification reaction was anhydrous ethanol (99,8 ${ }^{\circ}$ INPM), methanol and sodium methylate, propanol (99,5 ${ }^{\circ}$ INPM), butanol (99,5 $\left.{ }^{\circ} \mathrm{INPM}\right)$, sodium hydroxide e potassium hydroxide.

\subsection{Oil and ester characterization}

The acid value of oil was determined from AOCS Official Method Ca 5a-40 - Free Fatty Acid, and alkalinity by titration method AOCS Official Method Cd 3e-02 Determination of Alcalinity in Fats and Oils. Moisture was measured by volumetric Karl Fischer utilizing AOCS Ca 2e - 84 method. Density was determined by ASTM D 4052-09 and digital densimeter. Iodine index was calculated by AOCS Cd 1-25. ABNT NBR 15553 was employed for phosphorous measurement and quantification was conducted by inductively coupled plasma optical emission spectrometry (ICPOES).

For the fatty acid composition of oil, $100 \mathrm{mg}$ of sample and $2 \mathrm{~mL} \mathrm{n}$-heptane was added in a screw capped vials until oil solubilization. After that, $2 \mathrm{~mL}$ of $\mathrm{KOH}$ solution $\left(2 \mathrm{~mol} \mathrm{~L}^{-1}\right)$ in methanol was added and the tube was shaken for 5 minutes until phase separation. The supernatant was analyzed by gas chromatography.

A Varian Chromatograph CP-3800 with flame ionization detector (DIC) was used for the chromatographic analysis with a specific capillary column for the separation of fatty acids (BP-X70-SGE) of $30 \mathrm{~m} \times 0.25 \mathrm{~mm}$. The carrier gas used was helium, at a split ratio of 1:10. The analysis were performed with programming the column temperature, initiated at $110^{\circ} \mathrm{C}$, being heated to $250{ }^{\circ} \mathrm{C}$ at $5{ }^{\circ} \mathrm{C} \mathrm{min}-1$. The detector temperature was maintained at $220^{\circ} \mathrm{C}$ and the injector at $260{ }^{\circ} \mathrm{C}$. The identification of fatty acids was performed by comparison with the retention times of a mixture of fatty acid methyl ester standards.

From the results of the composition in fatty acids, the molar mass of the oil was determined according Geogorgianni et al. (2007).

\subsection{Transesterification of canola oil}

For the transesterification reactions, $100 \mathrm{~g}$ of canola oil were added in a three-necked flask, which was placed in a thermostatic bath $\left(30-70{ }^{\circ} \mathrm{C}\right)$ and kept under mechanical stirring (200-1000 rpm). The catalyst sodium methylate $\left(\mathrm{CH}_{3} \mathrm{ONa}\right)$, sodium hydroxide $(\mathrm{NaOH})$ or sodium potassium $(\mathrm{KOH})$ was then added. Samples were collected after 1, 2, 3, 5, 10, 15, 20, 30, 45, 60, 90 and 180 minutes and stored with $5 \mathrm{~mL}$ of $0.1 \mathrm{~mol} \mathrm{~L}^{-1}$ hydrochloric acid solution under refrigeration. The reaction products were separated by centrifugation, dried for 24 hours at $60{ }^{\circ} \mathrm{C}$ and analyzed by gas chromatography. 
The determination of the effects of the reaction conditions for biodiesel synthesis of canola oil was performed considering the following parameters: type and amount of catalyst, stirring speed, temperature and molar ratio oil: ethanol and the alcohol type.

The influence of the type of catalyst $\left(\mathrm{CH}_{3} \mathrm{ONa}, \mathrm{NaOH}\right.$ and $\left.\mathrm{KOH}\right)$ was carried out using 1:6 oil ethanol molar ratio, $1 \%\left(\mathrm{~kg} \mathrm{~kg}^{-1}\right)$ catalyst and $800 \mathrm{rpm}$ at $60{ }^{\circ} \mathrm{C}$. Thereafter, the concentration of sodium methylate catalyst $\left(0.5,1.0,1.5\right.$ and $\left.2.0 \% \mathrm{w} \mathrm{w}^{-1}\right)$ was assessed by setting the other parameters under the same conditions. The effect of the stirring speed was evaluated in reactions conducted with $1 \%\left(\mathrm{~kg} \mathrm{~kg}^{-1}\right) \mathrm{CH}_{3} \mathrm{ONa}$ at $60{ }^{\circ} \mathrm{C}$ and oil: alcohol molar ratio of 1:6. The influence of temperature was determined from reactions with $1 \% \mathrm{CH}_{3} \mathrm{ONa}$, molar ratio of 1:6 and $800 \mathrm{rpm}$. The oil:ethanol molar composition was studied considering the ratios $1: 6,1: 7.5,1: 9$ and $1: 12,1 \%\left(\mathrm{~kg} \mathrm{~kg}^{-1}\right) \mathrm{CH}_{3} \mathrm{ONa}$, temperature of $60{ }^{\circ} \mathrm{C}$ and $800 \mathrm{rpm}$. The effect of the type of alcohol used in the reaction was evaluated using an oil:alcohol molar ratio of $1: 6,1 \%\left(\mathrm{~kg} \mathrm{~kg}^{-1}\right) \mathrm{CH}_{3} \mathrm{ONa}$ at $60{ }^{\circ} \mathrm{C}$ and $800 \mathrm{rpm}$.

Finally, the biofuel synthesized under the best reaction conditions was analyzed in relation to the quality of the product, according to the Brazilian legislation.

\section{Results and discussion}

\subsection{Characterization of canola oil}

According to the results showed in Figure 1, monounsaturated oleic acid predominates in refined canola oil, followed by polyunsaturated linoleic acid. For this reason, the biodiesel produced with this material can present greater oxidative stability than the one obtained from the soybean oil, because in the latter, there is a higher mass concentration of linoleic acid (Ferrrari et al., 2005). This possibility can be reinforced by the lower iodine content of the raw material under study (Table 1) compared to that determined for refined soybean oil $(133,13)$ in the work of Ferrari et al. (2005). 


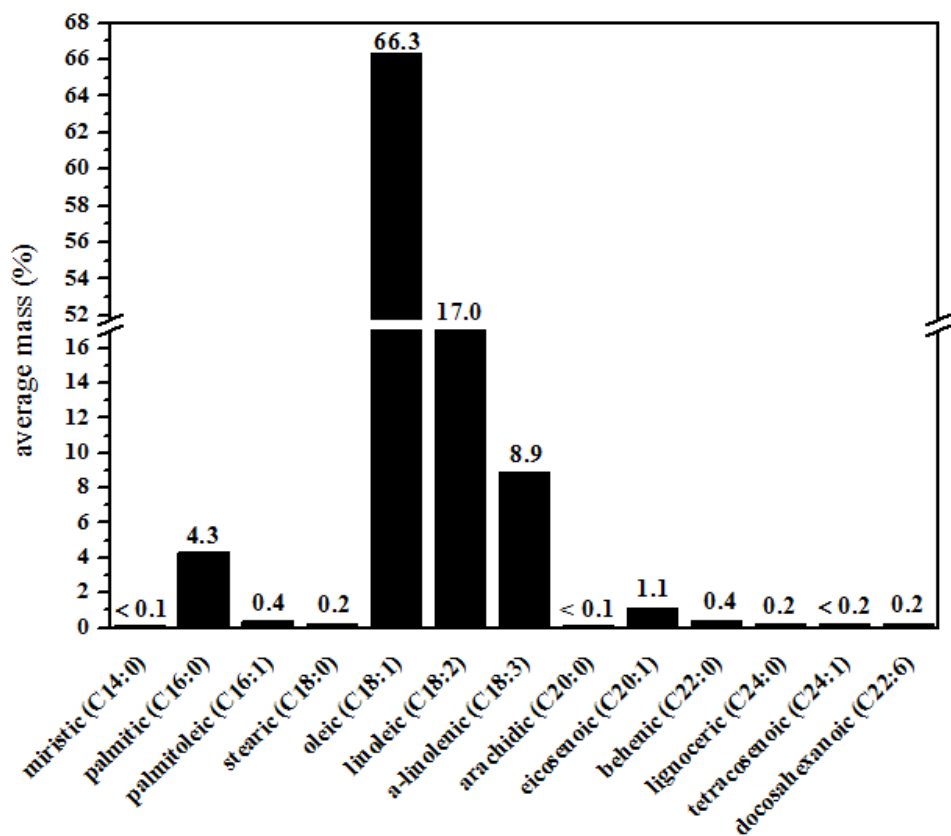

Figure 1. Fatty acid composition of refined canola oil.

Also with regard to the fatty acid composition shown in Figure 1, the average molar mass of canola oil was calculated, resulting in $841.3 \mathrm{~g} \mathrm{~mol}^{-1}$ (Georgogianni et al., 2009). This value is in agreement with values presented in the literature (Kwon et al. 2015; Jenab et al., 2014).

The other physical-chemical characteristics of refined canola oil are presented in Table 1. The acid value indicates that alkaline catalysis can be used for biodiesel production, since lipid materials with an index higher than $1 \%$ may impair the reaction yield due to saponification in the presence of inorganic bases (Mathiyazhagan and Ganapathi, 2011).

Table 1. Physical-chemical characteristics of refined canola oil.

\begin{tabular}{lc}
\hline \multicolumn{2}{c}{ Properties of Canola Oil } \\
\hline Acidity (\%) & $0.038 \pm 0.002$ \\
Soap (ppm) & $0 \pm 0.00$ \\
Moisture (\%) & $0.060 \pm 0.012$ \\
Density $\left(\mathrm{kg} \mathrm{cm}^{-3}\right)$ & $916.1 \pm 0.005$ \\
Iodine Index $\left({\left.\mathrm{g} 100 \mathrm{~g}^{-1}\right)}^{\text {Phosphorous }(\mathrm{ppm})}\right.$ & $109 \pm 1.28$ \\
\hline
\end{tabular}

According to Freedman et al. (1984) and Van Gerpen and Dvorak (2002), phosphorus levels should be controlled in order to avoid the reduction of catalyst efficiency and difficulty in the separation of glycerol. The amount of phosphorus found was $0.2 \pm 0.025 \mathrm{ppm}$, lower than the values found by some researchers such as Jang et al. (2012), which evaluated the synthesis of biodiesel from canola oil with $138 \mathrm{ppm}$ of phosphorus. Thus, probably the 
amount of phosphorus in the oil will have no negative impact on the quality esters that will be obtained by transesterification.

\subsection{Transesterification of canola oil}

\subsubsection{Influence of catalyst type}

As can be seen in Figure 2, the esters yields were $95.2 \pm 0.91 \%, 88.6 \pm 0.61 \%$, and $86.0 \pm 5.12 \%$ for $\mathrm{CH}_{3} \mathrm{ONa}, \mathrm{NaOH}$ and $\mathrm{KOH}$, respectively.

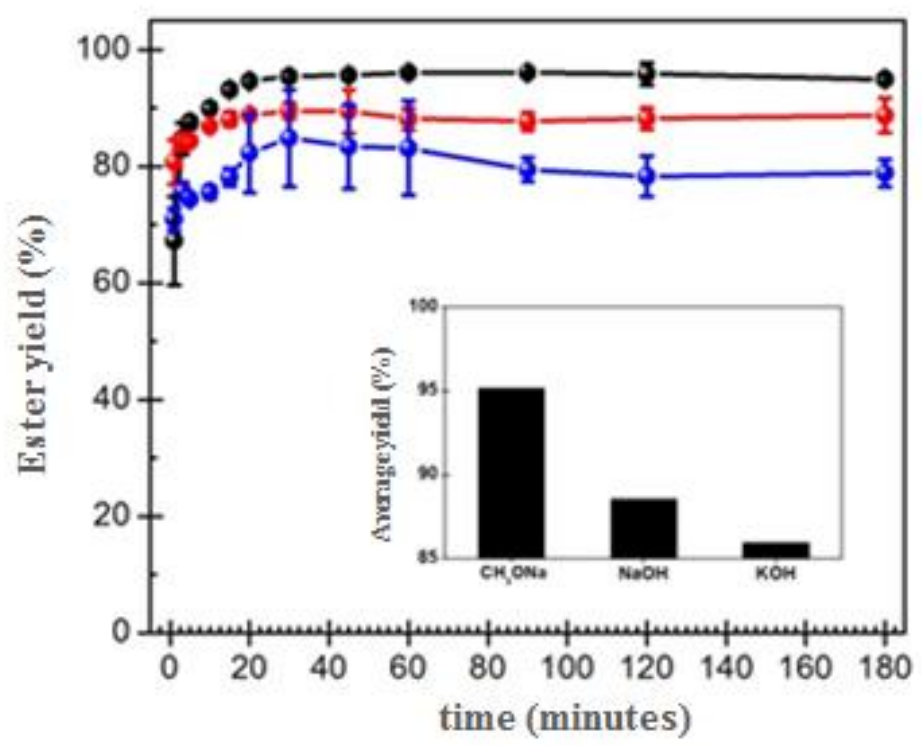

Figure 2. Esters Yield and average maximum yield (inset) as a function of time for catalyst type evaluation: $\mathrm{CH}_{3} \mathrm{ONa}$ (black); $\mathrm{NaOH}$ (red); and $\mathrm{KOH}$ (blue). The reaction conditions were: temperature of $60{ }^{\circ} \mathrm{C}$; oil:ethanol molar ratio of 1:6; $1 \%$ catalyst; and $800 \mathrm{rpm}$.

The higher ester yield obtained from the reaction using $\mathrm{CH}_{3} \mathrm{ONa}$ as catalyst may be associated with the generation of water in the ethoxide formation step when the sodium and potassium hydroxides are used, which causes the triacylglycerols hydrolysis and the free fatty acids saponification (Ejikeme et al.; 2010).

For the reactions performed with $\mathrm{KOH}$, it is verified that after reaching the maximum yield in $30 \mathrm{~min}$, there is a decrease in the values. This behavior can be attributed to the emulsification of the reaction medium, formed by ethyl esters and mono and diacylglycerols intermediaries (Freedman et al., 1986). Hence, the $\mathrm{CH}_{3} \mathrm{ONa}$ was selected for the study of the other reaction parameters, since the reactions conducted with this catalyst resulted in higher esters yield.

\subsubsection{Influence of catalyst amount}

In Figure 3, when the lowest amount of sodium methylate $\left(0.5 \% \mathrm{~kg} \mathrm{~kg}^{-1}\right)$ was used, 91.4 $\pm 2.23 \%$ ester yield was obtained in 45 minutes of reaction. This result was similar to that 
found by Freedman et al. (1984) for canola oil (90\%) after 50 min of the reaction conducted with an oil:alcohol molar ratio of 1:6. However, when $1 \% \mathrm{~kg} \mathrm{~kg}^{-1}$ of catalyst was used, it was observed an increase in the reaction rate and a higher yield among the quantities of catalysts evaluated $(95.2 \pm 0.91 \%)$, as can be observed in the Figure 3 .

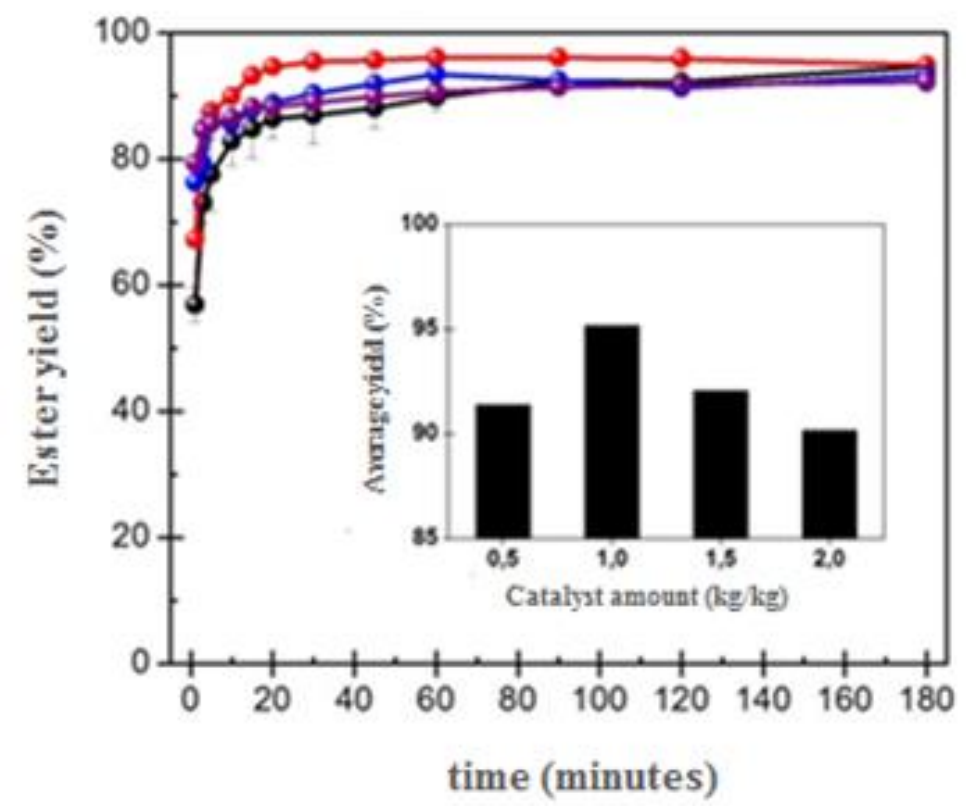

Figure 3. Esters Yield and average maximum yield (inset) as a function of time for $0.5 \mathrm{w} \mathrm{w}^{-1}$ (black), $1.0 \mathrm{w} \mathrm{w}^{-1}$ (red), $1.5 \mathrm{w} \mathrm{w}^{-1}$ (blue) and $2 \mathrm{w} \mathrm{w}^{-1}$ (purple) of $\mathrm{CH}_{3} \mathrm{ONa}$ catalyst. The reaction conditions were: temperature of $60^{\circ} \mathrm{C}$; oil:ethanol molar ratio of 1:6; and $800 \mathrm{rpm}$.

The amount of catalyst used $\left(1 \% \mathrm{~kg} \mathrm{~kg}^{-1}\right)$, which provided the highest yields in esters, is in accordance with reported in the literature (Meher et al., 2006; Georgogianni et al., 2009). Such a result can be explained by the fact that small amounts of catalyst limit the esters yield because the incomplete reaction. Large catalyst amounts, in high temperature and high molar ratio oil: alcohol, tend to favor the process of emulsification and saponification, which can cause the reduction of the reaction yield (Vicente et al., 2004; Knothe et al., 2006).

\subsubsection{Influence of stirring rate}

As shown in Figure 4, there was an increase in ester yield as the stirring rate was increased from $200 \mathrm{rpm}$ up to $800 \mathrm{rpm}$, but the values dropped for $1000 \mathrm{rpm}$. Regarding to the beginning of the reaction, no significant differences were observed when the speeds of $600 \mathrm{rpm}, 800 \mathrm{rpm}$ and $100 \mathrm{rpm}$ were used.

The lower reaction rates for $200 \mathrm{rpm}$ and $400 \mathrm{rpm}$ indicate that the overall reaction rate in the initial stages is controlled by interphase mass transfer between alcohol and oil (Noureddini e Zhu, 1997). From $600 \mathrm{rpm}$, it is possible that the mass control was smaller, leading to the greater ester yield obtained for the reaction at $800 \mathrm{rpm}$. 


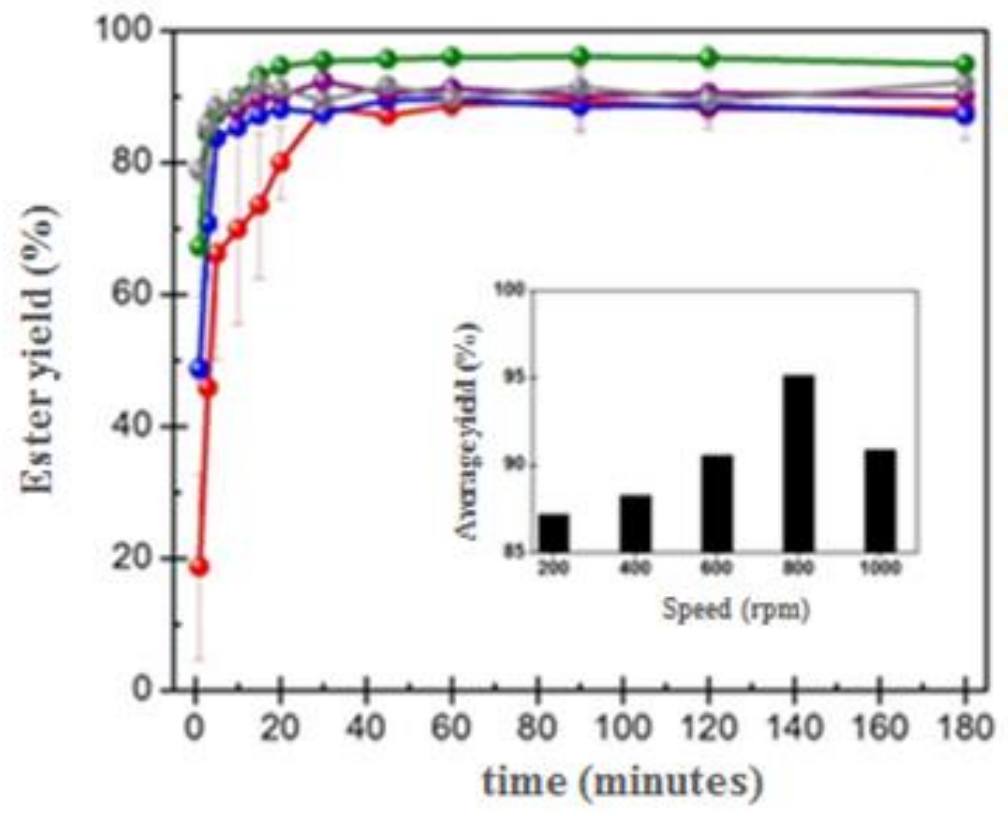

Figure 4. Esters Yield and average maximum yield (inset) as a function of time for stirring rates of $200 \mathrm{rpm}$ (red), $400 \mathrm{rpm}$ (blue), $600 \mathrm{rpm}$ (purple), $800 \mathrm{rpm}$ (green) and $1000 \mathrm{rpm}$ (gray). The reaction conditions were: temperature of $60^{\circ} \mathrm{C}$; oil:ethanol molar ratio of 1:6; and $1 \%$ sodium methylate.

Therefore, it can be assumed that the speed of $800 \mathrm{rpm}$ provided the best contact between the catalyst and the reactants in relation to the stirring rate of $600 \mathrm{rpm}$, as well as lower emulsification of the medium compared to the reaction conducted at $1000 \mathrm{rpm}$, since the formation of emulsion between the products of the reaction hinders the separation of the esters formed, resulting in a decrease in the ester yield (Vicente et al., 2005).

\subsubsection{Influence of temperature}

Although the reaction of transesterification occurs in three stages with reversible reactions and the increase of the temperature favor the direct reaction of ester formation, when the temperature of $70^{\circ} \mathrm{C}$ was used, this behavior was not observed (Figure 5). 


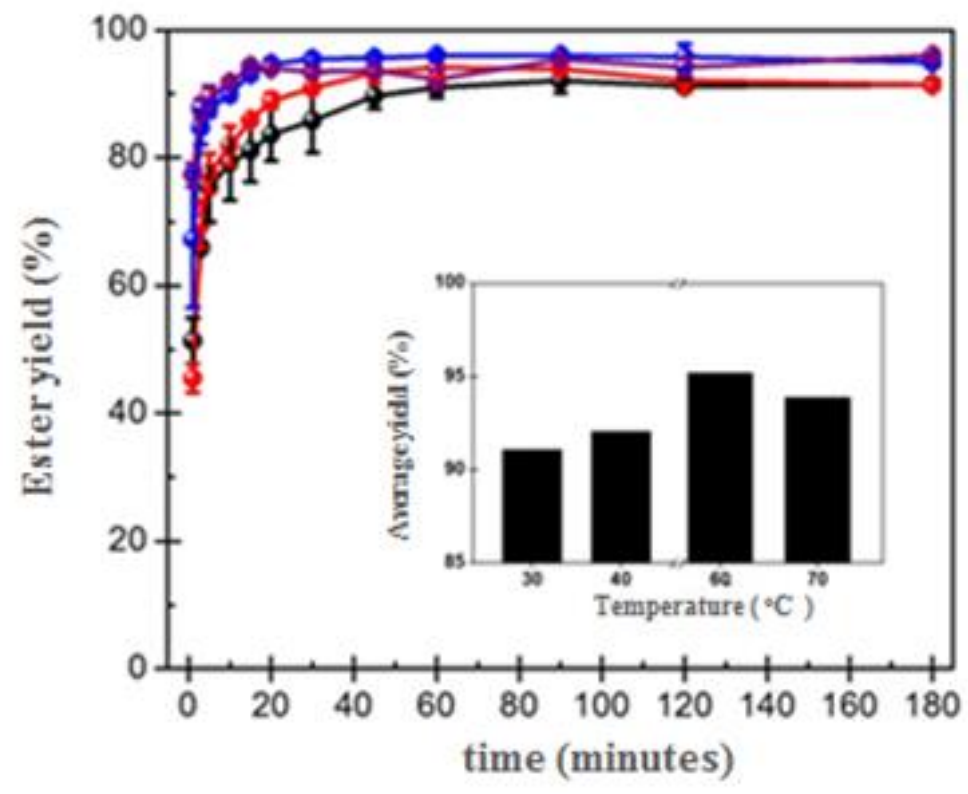

Figure 5 Esters Yield and average maximum yield (inset) as a function of time for reaction temperatures of $30{ }^{\circ} \mathrm{C}$ (black), $40{ }^{\circ} \mathrm{C}$ (red), $60{ }^{\circ} \mathrm{C}$ (blue) e $70{ }^{\circ} \mathrm{C}$ (purple). The reaction conditions were: oil:ethanol molar ratio of 1:6; $1 \%$ sodium methylate; and $800 \mathrm{rpm}$.

This was probably due to the greater proximity between the reaction temperature and the boiling point of the ethanol, in other words, it is possible that the evaporation of the alcohol limited the increase of the reaction yield (Nasir et al., 2014).

\subsubsection{Influence of oil to ethanol molar ratio}

It can be observed in Figure 6 that the increase in the amount of alcohol (oil:alcohol molar ratio from $1: 3$ to $1: 6)$ favored the displacement of the reaction equilibrium towards the products, leading to an increase ester yield. It can further be seen that the use of the oil: alcohol molar ratio of 1:7.5 resulted in the average ester yield of $92.3 \pm 2.07$, i.e., close to that obtained with the oil:alcohol molar ratio of 1:6. Then, the latter condition was considered more adequate by using less alcohol. It is also noted that the use of oil:alcohol molar ratios of 1:9 and 1:12 resulted in ester yield of $88.1 \pm 0.95$ and $78.1 \pm 1.38 \%$, respectively.

Such reductions may have been caused because too much alcohol interferes with the separation of esters and glycerol and it is possible that the diluted glycerol has caused apparent loss of the product due to foaming. 


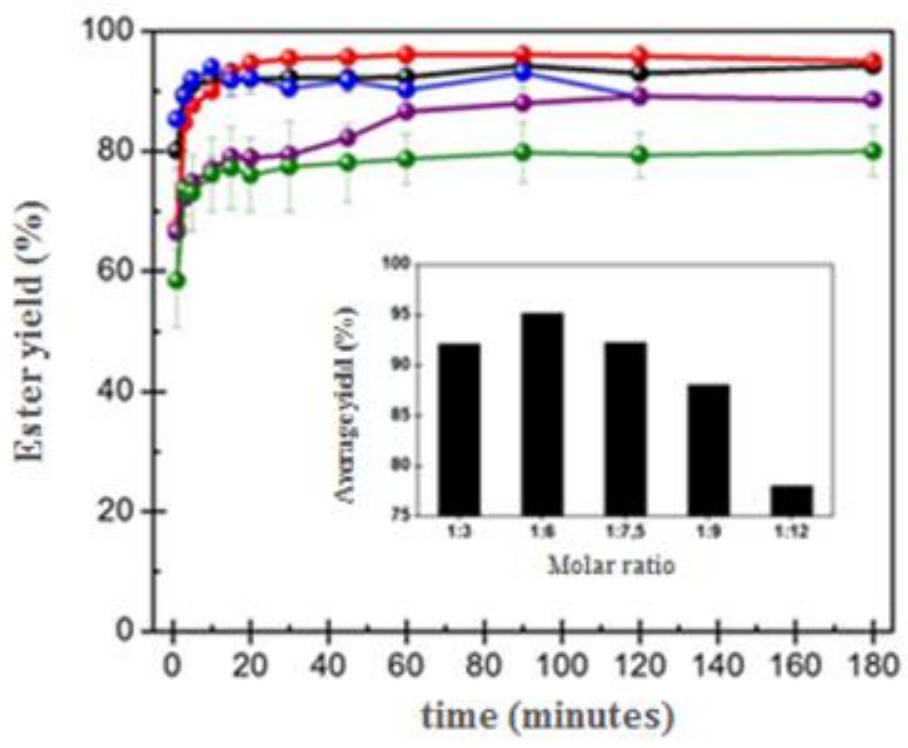

Figure 6. Esters Yield and average maximum yield (inset) as a function of time for oil:alcohol molar ratio of 1:3 (black), 1:6 (red), 1:7,5 (blue), 1:9 (purple) e 1:12 (green). The reaction conditions were: temperature $60{ }^{\circ} \mathrm{C} ; 1 \%$ sodium methylate; and $800 \mathrm{rpm}$.

The results reported in this study corroborate those obtained by Vyas et al. (2009), who reported lower yields of esters when using oil:alcohol molar ratios of 1:9 and 1:12.

\subsubsection{Influence of the alcohol type}

The use of methanol, ethanol, butanol and propanol as acyl acceptor in alkyl esters production was evaluated in the transesterification reaction, as shown in Figure 7.

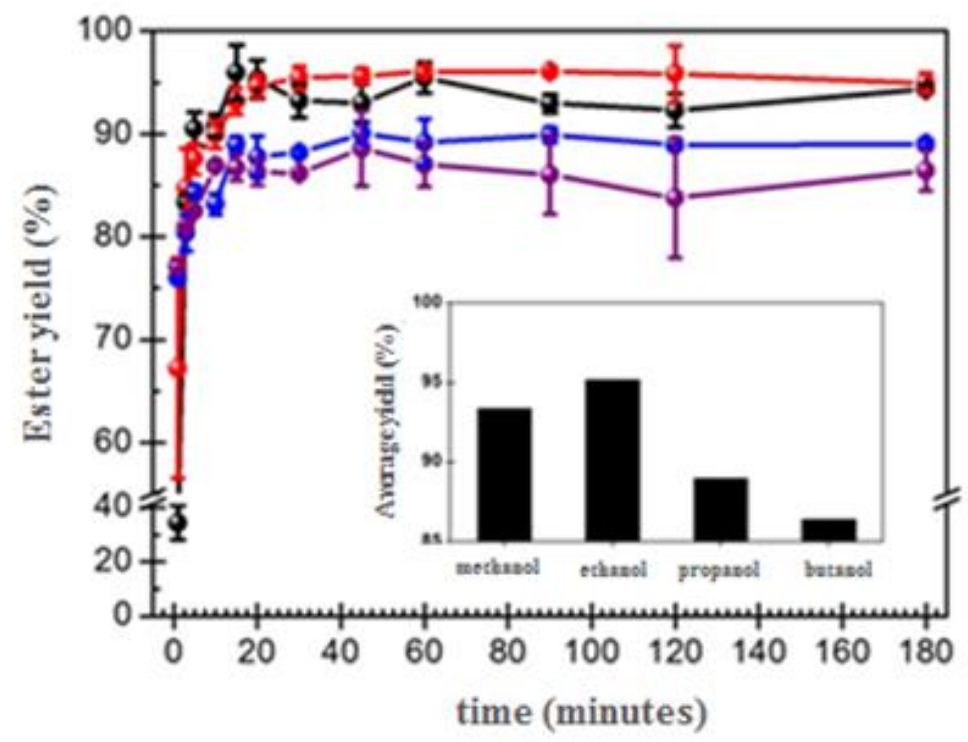

Figure 7. Esters Yield and average maximum yield (inset) as a function of time for alcohol type assessment: ethanol (red); methanol (black); propanol (blue); and butanol (purple). The reaction conditions were: temperature $60^{\circ} \mathrm{C}$; oil:ethanol molar ratio of $1: 6 ; 1 \%$ sodium methylate; and $800 \mathrm{rpm}$. 
Although methanol is widely used in the biodiesel industry, the higher amount of carbon in the molecule of the alcohol can be resulting in greater the amount of heat and cetane number in the biodiesel produced (Clark et al., 1998; Knothe et al., 2006; Baiju et al., 2009).

The values obtained demonstrate that in the first 5 minutes of reaction, the use of ethanol and methanol resulted in the worst performances from the point of view of the ester yield. After this period, the yields obtained using these alcohols exceeded the others, with maximum average yields of $95.32 \pm 2.68 \%$ for methanol and $96.1 \pm 1.26 \%$ for ethanol being reached.

According to the results, at the beginning of the reaction, the mass transfer between the phases was the limiting step, which may explain the kinetic behavior of reactions conducted with propanol and butanol, which have higher solubility in the oil (Baiju et al., 2009).

On the other hand, after the initial reaction period, it is reasonable to say that the limiting step was chemical kinetics, which explains the higher yields of the reactions performed with methanol and ethanol. Since these alcohols have a higher acidity, they are more reactive during the formation of the alkoxides and subsequent nucleophilic attack on the carbonyl present in triacylglycerols (Colucci et al., 2005).

\subsection{Characterization of the ester mixture}

The obtained and purified ethyl and methyl esters were characterized for evaluation of the product quality according to the ANP (Agência Nacional de Petróleo, Gás Natual e Biodiesel) norms and the results are presented in Table 2.

It can be observed that the mixture of esters produced by the conditions selected in this work exhibited characteristics close to those determined by the ANP specification, with the exceptions of some parameters such as free glycerin, monoacylglycerols and diacylglycerols for the ethyl esters and water content and diacylglycerols for the methyl esters.

It is also found that the esters obtained presented interesting characteristics, such as cold filter clogging point of -7 and $-8{ }^{\circ} \mathrm{C}$, amount of phosphorus of $0.1 \mathrm{mg} \mathrm{kg}^{-1}$, stability of 9.3 and $8.7 \mathrm{~h}$ without addition of antioxidant, and cetane number of 60.9 and 61.5 for methyl and ethyl esters, respectively. 
Table 2. Ester quality results obtained from the reaction conducted at a temperature of $60{ }^{\circ} \mathrm{C}$, oil:alcohol molar ratio of $1: 6,1 \%$ sodium methylate and $800 \mathrm{rpm}$.

\begin{tabular}{|c|c|c|c|c|c|}
\hline \multirow{2}{*}{ Analytical Item } & \multirow{2}{*}{ Methods } & \multirow{2}{*}{ Specification ${ }^{(1)}$} & \multirow{2}{*}{ Unity } & \multicolumn{2}{|c|}{ Results } \\
\hline & & & & Ethyl esters & Methyl esters \\
\hline Aspect & NBR 16048 & LII & - & - & - \\
\hline Specific Mass at $20^{\circ} \mathrm{C}$ & ASTM D 4052 & $850.0-900.0$ & $\mathrm{~kg} \mathrm{~m}^{3}$ & 875.1 & 879.2 \\
\hline Kinematic viscosity at $40^{\circ} \mathrm{C}$ & ASTM D 445 & $3.000-6.000$ & $\mathrm{~mm}^{2} \mathrm{~s}^{-1}$ & 4.790 & 4.493 \\
\hline Water content & ASTM D 6304 & $0.035 \max$ & $\mathrm{g} 100 \mathrm{~g}^{\mathrm{l}}$ & 0.031 & 0.037 \\
\hline Total Contamination & EN 12662 & $24.0 \max$ & $\mathrm{mg} \mathrm{kg}^{-1}$ & - & - \\
\hline Flash Point & ASTM D 93 & $100.0 \mathrm{~min}$ & ${ }^{\circ} \mathrm{C}$ & $>160$ & $>165$ \\
\hline Ester Content & EN 14103 & $96.5 \mathrm{~min}$ & $\mathrm{~g} 100 \mathrm{~g}^{-1}$ & 96.1 & 95.32 \\
\hline Carbon Residue ( $100 \%$ of the sample) & ASTM D 4530 & $0.05 \max$ & $\mathrm{g} 100 \mathrm{~g}^{-1}$ & 0.01 & 0.01 \\
\hline Sulfated Ash & ASTM D 874 & $0.020 \max$ & $\mathrm{g} 100 \mathrm{~g}^{-1}$ & - & - \\
\hline Total Sulfur & ASTM D 5453 & $10.0 \max$ & $\mathrm{mg} \mathrm{kg}^{-1}$ & 5.5 & 5.6 \\
\hline Sodium + Potassium & NBR 15553 & $5.0 \max$ & $\mathrm{mg} \mathrm{kg}^{-1}$ & 2.1 & 2.0 \\
\hline Calcium + Magnesium & NBR 15553 & $5.0 \max$ & $\mathrm{mg} \mathrm{kg}^{-1}$ & 0.7 & 0.4 \\
\hline Phosphorus & NBR 15553 & $10.0 \max$ & $\mathrm{mg} \mathrm{kg}^{-1}$ & 0.1 & 0.1 \\
\hline Copper band corrosion ( $3 \mathrm{~h}$ at $50 \mathrm{1C}$ ) & ASTM D 130 & $1 \max$ & - & - & lb \\
\hline Cold filter plugging point & ASTM D 6371 & $5 \max$ & ${ }^{\circ} \mathrm{C}$ & -7 & -8 \\
\hline Acid value & ASTM D 664 & $0.50 \max$ & $\mathrm{mg} \mathrm{g}^{-1}$ & 0.12 & 0.11 \\
\hline Free glycerol & ASTM D 6584 & $0.02 \max$ & $\mathrm{g} 100 \mathrm{~g}^{-1}$ & 0.006 & 0.009 \\
\hline Total glycerin & ASTM D 6584 & $0.25 \max$ & $\mathrm{g} 100 \mathrm{~g}^{-1}$ & 0.335 & 0.167 \\
\hline Monoglycerols & ASTM D 6584 & $0.80 \max$ & $\mathrm{g} 100 \mathrm{~g}^{-1}$ & 1.124 & 0.576 \\
\hline Diacylglycerols & ASTM D 6584 & $0.20 \max$ & $\mathrm{g} 100 \mathrm{~g}^{-1}$ & 0.243 & 0.604 \\
\hline Triacylglycerols & ASTM D 6584 & $0.20 \max$ & $\mathrm{g} 100 \mathrm{~g}^{-1}$ & 0.019 & 0.010 \\
\hline Methanol & EN 14110 & $0.20 \max$ & $\mathrm{g} 100 \mathrm{~g}^{-1}$ & 0.04 & 0.05 \\
\hline Iodine value & EN 14111 & - & $\mathrm{g} 100 \mathrm{~g}^{-1}$ & 115 & 111 \\
\hline Cetane number ${ }^{(2)}$ & ASTM D 6890 & - & - & 60.9 & 61.5 \\
\hline Oxidation stability at $110^{\circ} \mathrm{C}$ & EN 14112 & $6 \mathrm{~min}$ & hours & 9.3 & 8.7 \\
\hline
\end{tabular}

Tests carried out at the BSBIOS Marialva Laboratory, registered at the ANP by $n^{\circ} 044$.

(1) According to ANP Resolution $\mathrm{N}^{\circ} 14$, dated 05.11.2012 - DOU 18.05.2012.

(2) Analyzed by Lacaut Laboratory - UFRP.

\section{Conclusion}

From the study, the parameters for biodiesel production from canola oil could be evaluated. It was found that the use of ethanol and methanol, oil:alcohol molar ratio of 1:6, $1 \% \mathrm{CH}_{3} \mathrm{ONa}$ catalyst, $800 \mathrm{rpm}$ and temperature of $60{ }^{\circ} \mathrm{C}$ resulted in a product with characteristics close to those required by the Brazilian regulator.

The quality of the biofuels was mainly observed in relation to the cold filter clogging point, oxidation stability, phosphorus content and cetane number. So then, it can be seen that, in fact, the quality and composition of the lipid raw material, as well as the size of the carbonic chain of the alcohol are incorporated in the final ester mixture, being able to meet the requirements of the national market and favor the commercialization. 


\section{References}

ABNT NBBR 15553:2009. 2009. Biodiesel - Determination of calcium, magnesium, sodium, phosphorous and potassium content by inductively coupled plasma optical emission spectrometry (ICPOES).

ASTM D4052-09. 2009. Standard Test Method for Density, Relative Density, and API Gravity Liquids by Digital Density Meter. 2009. ASTM International, West Conshohocken, PA.

AVHAD, M.R., MARCHETTI, J.M. 2015. A review on recent advancement in catalytic materials for biodiesel production. Renewable and Sustainable Energy Reviews, 50, 696-718.

BAIJU, B.; NAIK, M.K.; DAS, L. M. 2009. A comparative evaluation of compression ignition engine characteristics using methyl and ethyl esters of Karanja oil. Renewable Energy, 34, 1616-1621.

BERGMANN. J. C., TUPINAMBA, D. D., COSTA, O.Y.A. ALMEIDA, J. R. M., BARRETO, C. C. QUIRINO, B., F. 2013. Biodiesel production in Brazil and alternative biomass feedstocks. Renewable and Sustainable Energy Reviews, 21, 411-420.

CÉSAR, A D., BATALHA, M. O., ZOPELARI, A. L. M. S. 2013. Oil palm biodiesel: Brazil's main challenges. Energy, 60, 485-491.

COLUCCI, J. A.; BORRERO, E. E.; ALAPE, F. 2005. Biodiesel from alkaline transesterification reaction of soybean oil using ultrasonic mixing. Journal of America Chemical Oil Society. 82, 525 - 530.

DEMIRBAS, A. 2005. Biodiesel production from vegetable oils via catalytic and non-catalytic supercritical methanol transesterification. Progress in Energy and combustion Science, 31, 466-487.

DEMIRBAS, A. 2007. Importance of biodiesel as transportation fuel. Energy Policy, 35, 4661-4670.

EJIKEME, P. M.; ANYAOGU, I. D.; EJIKEME, C. L.; NWAFOR, N. P.; EGBOUNU, A. C.; UKOGU, K.; IBEMESI, J. A. 2010. Catalysis in biodiesel production by transesterification process - an insight. E-Journal of Chemistry, 7, 1120 - 1132.

FERRAIR, R. A., OLIVEIRA, V. S.; SCABIO, A. 2005. Oxidative stability of biodiesel from soybean oil fatty acid ethyl esters. Scientia Agricola (Piracicaba Brazil), 62, 291-295.

FREEDMAN, B., BUTTERFIELS, R. O., PRYDE, E. H. 1986. Transesterification kinetics of soybean oil. J. Am. Oil. Chem. Soc, 63, 1375-1380.

FREEDMAN, B., PRYDE, E. H., MOUNTS, T. L.1984. Variables affecting the yield of fatty esters transesterified vegetable oils. J. Am. Oil Chem. Soc, 61, 1638-1643.

GEORGOGIANNI, A. K., KATSOUlIDIS, P.J., POMONIS, G., MANOS, M.G. 2009 Transesterification of rapeseed oil for the production of biodiesel using homogeneous and heterogeneous catalysis. Fuel Processing Technology, 90, 1016 - 1022.

ISSARIYAKUL, T.; DALAU, A 2010. Biodiesel Production from Greenseed Canola Oil, Energy Fuels, 24, 4652-4658. 
JANG, M. G., KIM, D. K., PARK, S. H., LEE, J. S., KIMA, S. W. 2012. Biodiesel production from crude canola oil by two-step enzymatic processes. Renewable Energy, 42, 99-104.

JENAB, E., TEMELlI, F., CURTIS, J. M., ZHAO, Y. Y. 2014. Performance of two immobilized lipases for interesterification between canola oil and fully-hydrogenated canola oil under supercritical carbon dioxide. LWT - Food Science and Technology, 58. 263-271.

KHATIWADA, D., LEDUC, S., SILVEIRA, S., MCCALLUM, I. 2016. Optimizing ethanol and bioelectricity production in sugarcane biorefineries in Brazil. Renewable Energy, 85, 371386.

KNOTHE, G. 2005. Dependence of biodiesel fuel properties on the structure of fatty acid alkyl esters, Fuel Process Technol, 86, 1059-70.

KULKARNI, M. G.; DALAI, A. K.; BAKHSHI, N. 2006. Utilization of green seed canola oil for biodiesel production. Journal of Chemical technology and Biotechnology ,81, 1886-1893.

KWON, K., VAHDAT, N., MBAH, J. 2015. Fatty acid methyl ester biofuels produced from canola oil with honeycomb monolithic catalysts. Fuel, 145, 116-126.

LI, Q.; XU, J.; DU, W.; LI, Y.; LIU, D. 2013. Ethanol as acyl acceptor for biodiesel production. Renewable and Sustainable Energy Reviews, 25, 742-748.

LUNA, F. M. T., CAVALCANTE, J. B., SILVA, F. O. N., CAVALCANTE JR. C. L. 2005. Studies on biodegradability of bio-based lubricants. Tribology International, v. 92, p. 301306.

MATHIYAZHAGAN, M.; GANAPATHI, A. 2011. Factors affecting biodiesel production. Research in Plant Biology, 1, 01-05.

MEHER, L. C., DHARMAGADDA, V. S. S.; NAIK, S. N. 2006. Optimization of alkalicatalized transesterification of Pongamia pinnata oil for production of biodiesel. Bioresource Technology, 97, 1392-1397.

MEHER, L. C., SAGAR, D. V., NAIK, S. N. 2004. Technical aspects of biodiesel production by transesterification: a review. Renewable \& Sustainable Energy Reviews, 10, 246-268.

MILAZZO, M.F; SPINA, F.; VINCI, A., ESPRO, C.; BART, J. 2013 Brassica biodiesels: Past, present and future. Renewable and Sustainable, Energy Reviews, 18, 350-389.

MOSER, B. 2011. Influence of extended storage on fuel properties of methyl esters prepared from canola, palm, soybean and sunflower oils, Renewable Energy, 36, 1221-1226.

NASIR, N. F.; DAUD, W. R. W.; KAMARUDIN, S. K.; YAAKOB, Z. 2014. Homogeneous alkaline catalyst to produce biodiesel in batch, plug flow and continuous stirred tanks reactors. International Chemical Engineering Jornal, 2014, 1 - 13.

NOUREDDINI, H.; ZHU, D. 1997. Kinetics of transesterification of soybean oil, Journal of American Oil Society, 74, 1457-1473.

OZCANLI, M., SERIN, H. 2011. Evaluation of soybean/canola/palm biodiesel mixture as an alternative. Jornal of Scientific \& Industrial Research, 70, 466-470.

SILVA, G. S., MARQUES, E. L. S., DIAS, J. C. T., LOBO, I. P., GROSS, E., BRENDEL, M., DA CRUZ, R. S., REZENDE, R. P. 2012. Biodegradability of soy biodiesel in microcosm experiments using soil from the Atlantic Rain Forest. Applied Soil Ecology, 55, $27-35$. 
VAN GERPEN J.H., DVORAK , B. The effect of phosphorus level on the total glycerol and reaction yield of biodiesel, The 10th Biennial Bioenergy Conference, Boise, ID, 2002. 22-26.

VICENTE, G., MARTÍNEZ, M., ARACIL. 2004. Integrated biodiesel production: a comparison of different homogeneous catalysts systems. Bioresource Technology, 92, 297305 .

VICENTE, G.; MARTÍNEZ, M.; ARACIL, J.; ESTEBAN, A. 2005. Kinetics of sunflower oil methanolisys. Industrial Engineering Chemical Research, 44, 5447 - 5454.

VYAS, A. P., SUBRAHMANYAM, N., PATEL, P. 2009. A. Production of biodiesel throught transesterification of Jatropha oil using $\mathrm{KNO}_{3} / \mathrm{Al}_{2} \mathrm{O}_{3}$. Fuel, 88, 625-628. 